\title{
СОВРЕМЕННЫЕ ТЕНДЕНЦИИ В РАЗВИТИИ И НАКОПЛЕНИИ ИНТЕЛЛЕКТУАЛЬНОГО КАПИТАЛА
}

\author{
(c) 2020 Левченко Лариса Владимировна \\ кандидат экономических наук, доцент \\ Самарский государственный экономический университет, Россия, Самара \\ E-mail: lvls@mail.ru
}

(c) 2020 Карпенко Ольга Анатольевна

кандидат экономических наук, ведущий специалист

АО «СамГЭС» (Самарагорэнергосбыт), Россия, Самара

В работе выявлены основные тенденции в развитии и накоплении интеллектуального капитала, которые классифицированы в группы основных тенденций с проведением их краткого исследования. Рассмотрены вопросы развития навыков современного человека, изменения функциональной роли человека в производственном процессе, в межличностных взаимоотношениях, в стратегиях развития современных предприятий. Также в работе приводятся примеры новейших и устаревающих профессий и исследуются объединяющие и другие тенденции современного общественноэкономического развития. Кроме того, в статье проведен расчет и сравнительный анализ экономических показателей, характеризующих исследуемые процессы.

Ключевые слова: интеллектуальный капитал, самозанятость, искусственный интеллект, интеграция, инновационное мышление, инновационные доходы, рента, жесткие и гибкие профессиональные навыки.

В настоящее время в новых условиях, несмотря на кризис весны 2020 года, развитие интеллектуального капитала, а также процессы его накопления идут ускоренными темпами. Об этом свидетельствует увеличение применения робототехники в медицинских учреждениях, на текстильных и фармацевтических предприятиях, возрастание спроса на интернет-услуги, интернет-вещи и удаленные рабочие места в связи с массовым введением режима самоизоляции. В современной экономике и обществе можно заметить новые тенденции в развитии и накоплении интеллектуального капитала, которые объединить в три крупных блока: образовательные и ресурсные, тенденции во взаимоотношениях между людьми, интеллектуально-рентные тенденции, функциональные и объединяющие. Рассмотрим каждый блок тенденций более подробно.

I. Образовательные и ресурсные тенденции

1. Новые подходы к процессу образования, грамотности и профессиональной ориентации

Современный технологический уклад, скорость распространения информации и быстрота принимаемых решений требует от человека все более широких компетенций. В связи с этим ключевыми навыками будущего является уже не

просто способность к повышению квалификации, но способность к постоянному и непрерывному обучению вплоть до профессиональной переориентации и смены профессии (как расширение знаний, так и узкая специализация). И здесь одно не противоречит другому, все зависит от меры ответственности и разграничения полномочий, степени проникновения вглубь решения задач и способности обучаться «в самом процессе трудовой деятельности». В отношении человека одной из главнейших тенденций становится непрерывное обучение, образование, повышение квалификации и развитие дополнительных навыков и знаний. По словам Ксавье Беттеля, мэра города Люксембурга и премьерминистра Люксембурга: «Главное ...инвестируйте в образование своих людей! За час я не научусь кататься на коньках, я буду падать и падать, но в конечном итоге - буду кататься. То же самое и с новой интеллектуальной экономикой» [1].

При этом помимо дополнительного образования сегодня особенно актуально повышение грамотности по гуманитарным направлениям специальностей. Во-первых,- это компьютерная грамотность, повышение навыков работы с информационными технологиями, новыми программами, приложениями и интерфейсами. 
Кроме того, зачастую в процессе трудовой деятельности выясняется, что необходимо обладать также и навыками программирования и работы с большими данными (цифровая грамотность).

Во-вторых, важна финансовая грамотность, значимость которой также трудно переоценить и которая возрастает в процессе перехода к цифровой экономике. Финансовая грамотность имеет чрезвычайно важное значение для каждого человека. Она начинается с оплаты коммунальных платежей, не переплачивая банковскую комиссию, продолжается и в профессиональной жизни, и в быту, и может заканчиваться, к примеру, профессиональной деятельностью по оптимальному распределению прибыли предприятия, или управлением собственным портфелем активов.

Для полной востребованности на рынке труда в будущем необходимо также быть юридически грамотным. Требуется знание не только основополагающих азов законодательства, но умение ориентироваться в действующей правовой базе и находить возможности законодательного решения той или иной проблемы. На практике в трудовой деятельности финансовая и юридическая грамотность тесно взаимосвязаны.

В настоящее время важной проблемой современных людей среднего возраста является необходимость смены профессии в зрелом возрасте, от 20-25 до 40-45 лет в связи с перестройкой рынка труда и отмиранием некоторых профессий. Люди сталкиваются с невостребованностью, потерей квалификации и навыков, а также необходимостью проведения поздней профориентации и получения второй профессии. Для них это связано с финансовыми и временными затратами, психологическим стрессом, потерей привычного круга общения и уклада жизни. Люди в возрасте, обремененные детьми - школьниками и студентами остаются один на один с рынком образовательных услуг и рынком труда. И здесь им должны бы оказать поддержку профориентационные центры, целью которых стала бы адресная помощь человеку в выборе дальнейшего направления обучения и трудоустройства в современных условиях, а также нахождения возможностей для текущего заработка, необходимого для содержания семьи и оплаты обучения. Однако подобных центров компленксной профориентации до настоящего времени не создано.

2. Развитие ресурсных человеческих ка- честв

Повышают качество и конкурентность человеческого капитала в профессиональной деятельности его ресурсные характеристики: институциональные мобильные возможности (способность водить машину, путешествовать на дальние расстояния), коммуникативные навыки (использование современных IT-средств общения, знание иностранных языков), социальные связи и контакты, а также личные качества, способности и возможности.

3. Развитие современных человеческих качеств и навыков

В настоящее время можно отметить учащение случаев смены работы, профессии, места жительства в связи с открывающимися новыми возможностями. Способности к адаптации и быстрой перемене своей жизни, не застревая в прошлом, становятся неотъемлемым атрибутом экономики и жизни будущего. В новейшем тренде сейчас стоит умение менять свое окружение и род деятельности при сохранении доверия к себе и своей репутации, умение находиться в движении и меняться в ногу со временем. Здесь важными качествами человека становится уже не просто жесткие профессиональные навыки (hard-skills), но также не менее важно умение приспосабливаться к сложившейся ситуации и гибкие (soft-skills) навыки, а также навыки продвижения себя и самопрезентации (self-skills). Сейчас наблюдается увеличение значимости гибких навыков общения и развития лидерских качеств, причем необязательно быть лидером всего коллектива, достаточно проявлять лидерство в рамках своей компетенции или круга интересов в своей области. Особенно это характерно для проектной деятельности.

II. Тенденции во взаимоотношениях между людьми

1. Развитие человеческих межличностных отношений

Сейчас к новым особенностям модели человеческих взаимоотношений относится возможность удаленной дружбы и общения на расстоянии посредством интернета. Аналогичным образом появляются и новые модели семейных отношений - жизнь в разных местах и даже в разных городах и государствах, удаленное общение членов семьи и друзей через интернет.

Наряду с движением прогресса информационных технологий, самое главное в будущем это духовное развитие человека. В решении во- 
проса построения социально-справедливого и эффективного общества интеллект и нравственность будут играть решающую роль, а нравственность, как известно,- одна из характеристик духовности [2]. Благодаря повышению значимости духовного и эмоционального интеллекта во взаимоотношениях между людьми возрастает качество общения.

Превалирующая роль в развитии взаимоотношений отводится женщинам. Они от природы обладают большими духовными качествами (эмпатией, качествами сострадания, милосердия, внимательности) и способностью быстрее обучаться, схватывать информацию и подстраиваться под меняющиеся внешние условия, обладают так востребованными сейчас гибкими навыками мышления и общения.

Подрастающая молодежь также несет на себе крупный заряд мотивации и качеств нового века: это быстрая обучаемость, пытливость ума, изобретательность, целеустремленность (качества будущих молодых ученых), нежелание идти у кого-либо на поводу, прогрессивность, проактивность и др.

2. Комплексное развитие всех подвидов человеческого капитала

Кроме того, важным является комплексное развитие человека в социальнокультурном плане, не только интеллектуальнопрофессиональном. Современным трендом является поиск своего хобби, досуга по интересам, в котором человек может проявить природные склонности и способности. К примеру, для женщин помимо танцев, йоги, фитнеса, это может быть рукоделие, кулинарные курсы, садоводство, цветоводство и множество других занятий. Вместе с восстановлением энергии и успокоением они ведут к развитию природных навыков, которые в дальнейшем даже могут вылиться в создание нового социального проекта, общественной организации, общественного движения или даже собственного бизнеса.

Всестороннее развитие также способствует интеллектуальному развитию человека, ведь новые идеи и решения могут прийти, к примеру, за рукоделием или в процессе музыкального творчества, чтения. Особенно эта тенденция характерная для женщин, которые стремятся сделать несколько дел одновременно и более приспособлены к многофункциональной деятельности.

В настоящее время человек, отличаясь от искусственного интеллекта, учится постоянному, системному мышлению и выходу за рамки стандартов и стереотипов. Он самостоятельно ставит себе новые задачи, ищет выходы из сложившихся ситуаций и при этом всесторонне развивается. В идеале нужно стремиться ко всестороннему развитию всех подвидов своего человеческого капитала. В современных крупных компаниях существует практика не только обучения сотрудников, но также их культурное развитие (походы в театр, выезды на природу, экскурсии, коллективное чтение), спортивные мероприятия, творческие занятия во внерабочее время, творческие конкурсы, мероприятия, досуг детей и многое другое.

III. Интеллектуально-рентные тенденции

1. Увеличение нематериальных активов и инвестиций в них

2. Увеличение интеллектуальных и инновационных доходов

О происходящих положительных изменениях в общественно-экономической жизни свидетельствует статистика показателей, характеризующих формирование, развитие и накопление интеллектуального капитала. Это показатели производительности труда, показатели, характеризующие интеллектуальные - нематериальные активы и интеллектуальные продукты, например, искусственный интеллект и результирующие показатели интеллектуальных доходов, например, инновационной ренты.

Из Таблицы 1 мы видим возрастание значений каждого показателя (рост производительности труда, увеличение стоимости нематериальных активов, увеличение проектов искусственного интеллекта и машинного оборудования, а также рост значений инновационной ренты), что свидетельствует в целом об увеличении процессов формирования, развития и накопления интеллектуального капитала.

IV. Функциональные тенденции

1. Новые модели производства и потребления, а также руководства и управления

Среди новых моделей производства и потребления можно выделить две параллельно идущие тенденции: новые институты трудовых отношений по найму - фрилансерство и самозанятость и новые модели потребления, связанные с непосредственным заказом товаров и услуг через интернет и практически мгновенным потреблением.

Сейчас как никогда наблюдается увеличение случаев фрилансерства, а начиная с 2020 
Таблица 1. Статистика изменения показателей, характеризующих формирование и развитие интеллектуального капитала

\begin{tabular}{|c|c|c|c|c|c|}
\hline \multirow[b]{2}{*}{ Годы } & \multirow{2}{*}{$\begin{array}{c}\text { Рост производи- } \\
\text { тельности труда } \\
\text { Индекс произ- } \\
\text { водительно- } \\
\text { сти труда по } \\
\text { экономической } \\
\text { деятельности }\end{array}$} & \multicolumn{3}{|c|}{ Рост внедрения ИИ } & \multirow[b]{2}{*}{$\begin{array}{c}\text { Рост инноваци- } \\
\text { онной ренты, } \\
\text { млн. руб. }\end{array}$} \\
\hline & & $\begin{array}{c}\text { Стоимость НМА, } \\
\text { трлн. долл. }\end{array}$ & $\begin{array}{c}\text { Динамика рынка } \\
\text { ИИ и машинного } \\
\text { оборудования, } \\
\text { млрд. руб. }\end{array}$ & $\begin{array}{c}\text { Динамика коли- } \\
\text { чества проектов } \\
\text { ИИ и машинного } \\
\text { оборудования, } \\
\text { млрд. руб. }\end{array}$ & \\
\hline 1 & 2 & 3 & 4 & 5 & 6 \\
\hline 2020 (прогноз) & & & 28 & & \\
\hline 2018 & 102,3 & & & & \\
\hline 2017 & & & 0,7 & 74 & 27112 \\
\hline 2016 & & 47,6 & & 71 & 25755 \\
\hline 2015 & 98,9 & 46 & & 17 & 25509 \\
\hline 2014 & & 43 & & & 24321 \\
\hline 2010 & & 32 & & & \\
\hline
\end{tabular}

Составлено автором. Данные взяты из следующих источников:

Графа 2: Индекс производительности труда рассчитывается Федеральной службой государственной статистики в целом по экономике и отраслям экономики, продукция которых реализуется преимущественно по рыночным ценам. Индекс изменения производительности труда по экономике в целом рассчитан как частное от деления индексов физического объема ВВП и индекса изменения совокупных затрат труда. По отраслям экономики индекс производительности труда рассчитывается как частное от деления индексов физического объема добавленной стоимости и изменения совокупных затрат труда. Индексы изменения ВВП и добавленной стоимости рассчитаны исходя из абсолютных значений этих показателей в постоянных ценах;

Индексы изменения совокупных затрат труда определены на основе трудовых затрат на всех видах работ, включая дополнительную работу и производство продукции для собственного потребления;

Индекс производительности труда в соответстии с классификатором ОКВЭД2 публикуется, начиная с данных за 2015 год. Результат ретроспективного пересчета динамического ряда в ОКВЭД2, начиная с 2011 года будет опубликован в апреле 2020 года; Труд и занятость в России. 2019: Стат.сб./Росстат Т78 М., 2019. 135 с. - С. 65.

Графа 3: Global Intangible Finance Tracker 2017. Reputation Capital Griup Режим доступа: https://reputationcapital.blog/2017/07/ cena-nematerialnyh-aktivov-v-2017-godu/

Графа 4,5: Актуальные тенденции рынка искусственного интеллекта и машинного обучения Исследование ТАdviser и «Инфосистемы Джет». Октябрь 2017, Москва. Режим доступа: https://www.tadviser.ru/images/4/41/\%D0\%98\%D1\%81\%

Графа 6: Данные взяты на сайте Федеральной службы государственной статистики: Режим доступа: http://www.gks.ru/bgd/ regl/b18_61/Main.htm, https://www.hse.ru/data/2019/05/07/1502498137/in2019.pdf

года массовое введение самозанятости для желающего населения и увеличение развития малого предпринимательства. С начала 2019 года в четырех регионах, где проходит эксперимент, самозанятыми зарегистрировалось уже около 30000 человек, что в 15 раз больше, чем за полтора года предыдущей попытки, в которой участвовала вся Россия [3].

Вместе с этим наблюдается развитие новейших рынков благ и услуг, и создания новых производств, ориентируясь на новые человеческие потребности. Особенностью современного процесса потребления является большие возможности обратной связи с поставщиками продуктов и услуг, возможности доставки в сети и более быстрый процесс потребления, снижение трансакционных финансовых, временных и человеческих затрат на поиск продукции и ее донесение. Все более сокращается и сводится к нулю временной лаг между возникновением потребно- сти и ее удовлетворением (потреблением продукта/услуги), а также все больше происходит их потребление по индивидуальным заказам.

В моделях руководства и управления в связи с автоматизацией производственных и управленческих процессов приходит необходимость совершенствования методов руководства предприятием и решения новых управленческих задач. Это непрерывная работа в режиме многозадачности, многофункциональности, расширение кругозора профессиональных интересов и областей знаний, а в некоторых вопросах - наоборот, углубление знаний, работа в режиме строгой регламентации и ограниченного времени, умение быстро реагировать на ситуации, быстро принимать решения и делегировать полномочия. При этом все более повышается значимость качества общения и своевременного владения информацией. По словам главы Агентства стратегических инициатив С. Чупшевой на Санкт- 
Петербургском международном экономическом форуме-2019 «к одним из ключевых навыков профессионального общения и самосознания относятся способности к конструктивной критике, мультикультурность, а также умение работать в команде» [4].

Также происходит смещение производительной функциональной роли человека с менеджера и управленца до куратора и руководителя проекта, группы или направления деятельности, тем самым увеличивая его функциональные обязанности мониторинга, контроля и значимость качества его деятельности.

2. Новые стратегии развития предприятий - массовое внедрение инноваций и искусственного интеллекта и экологизация

Для крупного предпринимательства главнейшей выигрышной и новейшей тенденцией является увеличение процессов разработки и внедрения искусственного интеллекта, в связи с чем отходят в прошлое многие виды человеческого труда, как ручного, так и интеллектуального. По экспертным оценкам, рынок искусственного интеллекта в перспективе будущих 5 лет может увеличиться чуть ли не в несколько раз и повысит экономический рост. Ожидается, что к 2035 году технологии на основе искусственного интеллекта увеличат производительность корпораций в 16 отраслях промышленности в 12 странах мира в среднем на 38\%. Об этом свидетельствуют данные опроса 1911 экспертов по рискам, проведенного Allianz в 2018 году [5].

Следом идет тенденция всеобщего применения инноваций, начиная от моделей и образцов новых продуктов и технологий и заканчивая институциональными инновациями и даже новшествами в психологическом развитии человека. Современное интеллектуальное производство уже базируется на технологиях новейшего технологического уклада. Это автоматизация и роботизация промышленного производства, внедрение вычислительной техники как в производство, так в сферу услуг и управление.

Кроме того, важнейшим трендом становится экологическая направленность производства, создание новых инновационно-экологичных товаров и услуг, формирование соответствующих рыночных ниш и всеобщей пропаганды сбережения природы. По итогам 2018 года более чем из ста бизнес-стратегий экологичных производств создания компаний-стартапов около половины оказалось проектами российских разработок [6].

3. Изменения на рынке труда и в профессиональном развитии человека: новые виды деятельности и новые профессии, отмирание старых профессий, развитие надпрофессиональных навыков

Происходящие изменения на современном рынке труда связаны с отмиранием некоторых профессий в связи с развитием деятельности в сети, автоматизацией и внедрением искусственного интеллекта и появлением новых профессий будущего. Это профессии, во многом связанные с работой в сети: сетевой врач, интропедагог, модератор, проектировщик новых моделей, координатор онлайн-платформ, а также ментор, консультант по здоровому образу жизни, роботооператор, арт-оценщик, ситуативный куратор, акмеолог и др. Среди профессий, уходящих в прошлое, можно отметить сметчика, операциониста, оператора услуг, копирайтера, библиотекаря, маклера, журналиста, логиста, переводчика и др. Их уход в основном связан с развитием роботоинженерии и технологий искусственного интеллекта.

Кроме того, для современного человека помимо профессиональных, также необходимо развитие надпрофессиональных навыков. Можно выделить порядка 11 современных надпрофессиональных навыков в развитии человеческого капитала. Среди них инновационное, экологичное и системное мышление, управление проектами, работа в условиях неопределенности, программирование и IT-навыки, художественное творчество, мультиязычность и мультикультурность, межотраслевая коммуникация, клиентоориентированность, бережливое производство.

4. Тенденция к быстрому развитию событий и постоянный дефицит времени

Ежедневно мы наблюдаем и ощущаем на себе необходимость быстрого передвижения, быструю передачу информации, быстрое обучение, принятие решений и т.д., которое с одной стороны, вводит людей в определенные стрессовые ситуации и режим нехватки времени, а с другой - повышает значимость умения грамотного распределения и использования своего времени.

V. Объединительные тенденции

1. Совмещение профессиональной и общественной деятельности 
Новые стандарты жизни диктуют необходимость исполнения множества ролей и в тренде - многофункциональность жизнедеятельности. Люди стремятся получить несколько образований и профессий, строить одновременно несколько карьер (профессиональную, смежную профессиональную, научную, преподавательскую, экспертную, возможно творческую), создавать семью, вести общественную или социальную деятельность, заниматься своим развитием и хобби.

Наблюдается стремление к комплексному развитию человеческого капитала, к максимальному развитию собственных качеств и способностей, интересов, а также к поиску новых своих талантов и возможностей.

2. Возрастание командной деятельности с участием специалистов разных направлений и сфер: проектной деятельности, деятельности по проведению когнитивных исследований (на стыке наук лингвистики, философии, психологии, нейробиологии, физики и др.), предполагается введение в практику коллективной защиты дипломного проекта с вовлечением специалистов разных наук и сфер (математиков, физиков, программистов, экономистов, филологов и др.)

3. Усиление интеграционных процессов

В будущем предполагается дальнейшее усиление процессов объединения, обмена и всевозможных интеграционных мировых тенденций. По мнению гендиректора «Росатома» Алексея Лихачева, в рамках одной страны невозможно создать среду, ориентированную на человека, его потребности и меняющийся мир [7], необходим согласованный порядок действий мирового сообщества. В свете последних событий мы видим объединения государств в борьбе с коронавирусом, экономическим кризисом, военной угрозой и терроризмом, а также инновационные и научные международные общественные объединения.

Итак, вышеперечисленные тенденции свидетельствует о том, что в настоящее время научно-технический прогресс и человеческое интеллектуальное развитие движутся все более ускоряющимися темпами, которые приводят к трансформационным процессам существующей общественно-экономической системы.

\section{Библиографический список}

1. Пока к власти не пришел искусственный интеллект - у нас есть шанс // Авторские колонки. Режим доступа: https://rb.ru/opinion/interesno-na-otkrytyh-innovaciyah/

2. Упазалы С. Интеллектуальная экономика - технологические вызовы XXI века. Экономика. Избранные труды. VI Том. Издание 2 / С. Ю. Глазьев, А.Е. Арменский, Е.А. Наумов / Алматы, 2011. - 320 с. - С. 76.

3. С 2020 года закон о самозанятых заработает по всей России Режим доступа: https://zen.yandex. ru/media/id/5aa8d5d9a86731ea4d5fd077/s-2020-goda-zakon-o-samozaniatyh-zarabotaet-po-vseirossii-5c7149125b728d00afce5e45

4. Там же.

5. лековкин Н. Какие риски искусственный интеллект создает для экономики. Финансы и инвестиции. Страхование // Forbes. Режим доступа: https:/www.forbes.ru/finansy-i-investicii/363499-vosstanie-mashin-kakieriski-iskusstvennyy-intellekt-sozdaet-dlya

6. Успехи российских стартапов за рубежом. Режим доступа: https://rb.ru/longread/winners-2018/

7. Глава «Росатома» А. Лихачев о стратегии, новых рынках, СМП Режим доступа: https://ru.reuters.com/article/ idRUKCN1TP218-ORUBS 